\title{
Endogenous Thrombin Potential Time to Peak Relative Measurement
}

National Cancer Institute

\section{Source}

National Cancer Institute. Endogenous Thrombin Potential Time to Peak Relative Measurement. NCI Thesaurus. Code C102270.

A relative (ratio or percentage) measurement of the time it takes to generate the maximum concentration of thrombin. 